\title{
Short time, few available resources and need for measuring the strain in parents of children with chronic diseases: Utility of the Family Strain Questionnaire, Short Pediatric Form
}

\author{
Silvia Rossi Ferrario ${ }^{1}$, Giulio Vidotto ${ }^{2}$, Manuela Monti ${ }^{3}$, Cristiana Risso ${ }^{4}$ \\ 1. Psychology Unit, 'S. Maugeri' Foundation, IRCCS, Scientific Institute of Veruno (NO), Italy. 2. Department of General \\ Psychology, University of Padua, Padua, I taly. 3. Pediatric Orthopedics and Traumatology Department, Rizzoli Orthopedic \\ Institute, Bologna, Italy. 4. Pediatric Respiratory Diseases Unit, Children Hospital Regina Margherita S. Anna (CHRMSA), \\ Turin, Italy.
}

Correspondence: Giulio Vidotto. Address: Department of General Psychology, University of Padua, Via Venezia 8, 35131 Padova, Italy. E-mail: giulio.vidotto@unipd.it

Received: July 29, 2013

DOI : $10.5430 /$ jnep.v4n3p79
Accepted: September 17, 2013

Online Published: October 31, 2013

\begin{abstract}
Measuring caregivers' strain due to chronic disease of childhood is an important complement of the quality of children's care but it may imply resources not always available. Short questionnaires may then be useful, especially for clinical nurses and care-teams. In this study we present the Family Strain Questionnaire-Short Pediatric Form (FSQ-SPF), which is brief, easy to use, and does not require any specific psychological training. The questionnaire was administered to 96 parents of children affected by genetic/congenital or acquired diseases recruited at two pediatric hospitals. The psychometric properties were analyzed in the context of the requirements for scale construction of the Rasch model. The characteristics of the parents and their levels of strain were then estimated. The parents analyzed (n.96) showed to suffer from severe strain over time, which was independent of the severity of the child's disability. This was particularly true for mothers with lower levels of education (i.e. one-third of the sample). Forty-four percent of these mothers experienced a difficult relationship with their partner. In general, more than $40 \%$ of the subjects declared economic difficulties, reduced social life and problems to move to hospital or for medical visits. The FSQ-SPF seems to be a useful and practical instrument for the evaluation of caregivers' strain in a pediatric/adolescent context. It provides an appropriate and brief screening test, helping to target interventions and improving the quality of care.
\end{abstract}

\section{Key words}

Caregiving, Child, Chronic disease

\section{I ntroduction}

Caregiving strain, which is the totality of the burdens that attend caring for an ill individual, is well-documented in caregivers of adults (age $\geq 18$ years) with chronic conditions, and many questionnaires have been created to measure this type of caregiver stress or some aspects of it ${ }^{[1,2]}$. In contrast, the caregivers, usually parents, of children and adolescents have received less attention, despite an increase in chronic childhood conditions ${ }^{[3]}$. Parents' strain in managing major 
chronic childhood diseases, with the exception of asthma and congenital heart diseases, has been scarcely investigated. The existing international literature shows that the caregiving-related problems that occur in adult, pediatric, and adolescent contexts seem to be similar, even when different methodologies, times of assessment, and illnesses are taken into account. The emotional problems ${ }^{[4]}$, sleep disruption ${ }^{[5]}$, poor physical and psychological health ${ }^{[6]}$, financial burdens ${ }^{[7]}$, little time for themselves or people other than the patient ${ }^{[8]}$, social isolation ${ }^{[9]}$, are commonly discussed by all kinds of caregivers, who also describe a relationship between their psychological and social health and their patients' behavioral and emotional symptoms ${ }^{[10]}$.

Despite these findings, some differences may characterize those who care for children: First, they are generally younger, of working age, and at a point in life when most people invest their efforts in long-term projects. Second, they may have other children or other family members who need attention and care ${ }^{[11]}$. Third, they may be young couples who need to perceive this role as distinct from their role as parents ${ }^{[12]}$. Finally, this caregiving responsibility is often long term; it starts at the child's birth and continues throughout the life of the child. Measuring the caregiving strain is an important step in assisting caregivers but it is not always possible, due to the scarcity of available resources and little time to dedicate. To overcome this difficulty, this study aimed to deepen knowledge of the caregiving-related problems in parents of children with chronic disabilities, by the means of the Family Strain Questionnaire Short ${ }^{[13]}$ Pediatric Form (available on request to Rossi Ferrario).

\section{Methods}

\subsection{Participants and procedure}

The study was part of a long-term project investigating measurements of caregivers' strain, which was started at the S. Maugeri Foundation of Veruno and approved by the Foundation's internal ethics committee. Parents were recruited at two pediatric hospitals in northern Italy: the Rizzoli Orthopedic Institute (ROI) in Bologna and Children's Hospital Regina Margherita S. Anna (CHRMSA) in Turin. The ROI Pediatric Orthopedics and Traumatology Department provides medical and surgical treatment for growing patients with musculoskeletal system disorders, especially those due to congenital neurological diseases (spina bifida or cerebral palsy, for example) or benign tumors. CHRMSA's Pediatric Respiratory Disease Unit runs the Cystic Fibrosis Center of the Piedmont and Valle d'Aosta and a chronic respiratory failure center. An expert psychologist explained the study to the parents, who signed informed-consent forms, and subsequently responded to the Family Strain Questionnaire-Short Pediatric Form (FSQ-SPF). For the purpose of our study, we decided to consider the data obtained by 96 parents, one for every child.

\subsection{Measure}

The FSQ-SPF is a modified version of the FSQ-SF for adults, whose detailed construction was previously published ${ }^{[13,14]}$.This questionnaire measures the psychophysical risk due to caregiving strain, regardless of the referent disease. Validated by Rasch analysis ${ }^{[13]}$, it consists of 30 yes (score 1)/no (score 0 ) items, which measure the unique dimensions of strain. The items are listed in order of the severity of stress, corresponding to the results of the Rasch item analysis, so the scale ranges from the lowest to the highest stress indicators. The score, immediately obtained, assigns the subject a different grade of psychophysical risk based on the need for psychological consultation: area OK (score 1 to 6 : the caregiver is coping well with the situation); area $\mathrm{R}$ (score 7 to 12: the caregiver presents some maladjustment, and it is recommended to have a specific consultation in case of the situation worsen); area SR (score 13 to 20: the caregiver presents evidence of strain, and it is strongly recommended to have a psychological examination and counseling); and area $\mathrm{U}$ (score 21 to 30: the caregiver presents great strain and high psychological risk, making it urgent to be seen by a psychologist or a psychiatrist. A safeguarding scoring rule prevents the likelihood of false-negative diagnoses: For caregivers with scores less than 20, the total score is increased by 1 for each "yes" answer to any question numbered 24-30. On the other side of the items-page are the caregiver's and patient's demographic cards. This page also contains a graphic 
device resembling a thermometer that facilitates scoring; one end of the graphic indicates a low level of strain, and the other end indicates a higher, even dangerous level of strain.

For this study, some changes were made to the questionnaire after a focus group was made between two authors of this study, who regularly work with parents and children, others team members and a group of 10 parents who were asked to collaborate. We substituted the word "patient", which was in the original questionnaire for adults, with the word "son/daughter" and changed 3 items, which in the original form explicitly referred to the patient's death and might be too disturbing for the parents to consider. In item 4, "I sometimes think about the death of the patient" was changed to "I sometimes think about the possibility that my son's/daughter's condition could get worse;" in item 25, "I sometimes have the impression that I have lost the patient" was changed to "I sometimes have the impression that I could lose my son/daughter;" and in item 29, "I would like to talk about the possible loss of the patient" was changed to "I would like to talk about the possible worsening of my son's/daughter's illness. Keeping in mind the need to explore the level of the caregiver's strain in relation to the child's condition, we created a semi-structured interview preceding the questionnaire itself in order to collect data about the child's dependence or autonomy in eating, walking, self-dressing, self-washing, urine and feces control, speech, and comprehension. We also asked for the caregiver's perception of the child's awareness of the condition and emotional well-being. Finally, we added a question about any difficulties in caregiver's relationship with a partner caused by the child's illness.

\subsection{Statistical analysis}

The data were first analyzed in order to ensure that the questionnaire had the same psychometric characteristics of the original form. We referred to the Rasch model for dichotomous data and used Winsteps ${ }^{[15]}$ and an R package (ltm) for latent variable modeling and item response theory analyses ${ }^{[16]}$. Frequency distribution was used for all the qualitative variables. Student's t-tests for independent samples were performed in order to investigate any differences between subjects with extremely severe strain (FSQ-SPF score $\geq 21$ ) and others.

\section{Results}

\subsection{Previous Rasch analysis of $\mathbf{3 0}$ FSQ-SF items}

A reverse-scored item (1) was recoded so that a caregiver's response of ' 1 ' always indicated a higher level of stress than a ' 0 ' response; moreover, a participant with a score of 0 was excluded. A special function was applied to perform a parametric bootstrap goodness-of-fit test using Pearson's chi-squared statistic (Rizopoulos, 2009). In particular, the null hypothesis stated that the observed data were generated under the Rasch model, with parameter values the maximum likelihood estimates. To test this hypothesis, 50 samples were generated under the Rasch model using these parameters, and the Pearson's chi-squared statistic Ti was computed for each data-set $(i=1, \ldots, 50)$, so that the $p$-value was approximated by the number of times $\mathrm{Ti} \geq$ Tobs +1 divided by $50+1$ (where Tobs denotes the value of the statistic in the original dataset). Examination of the analytical output showed potential observance of the measurement properties required by the Rasch model. Indeed, goodness-of-fit, using Pearson chi-squared, based on 50 datasets, and showing a non-significant p-value of 0.36, suggested an acceptable fit of the model (Rizopoulos, 2009). Reliability (alpha $=0.85$; 0.83 winsteps) remained close to that observed in previous analyses (Vidotto et al., 2010), in which item-total biserial correlations revealed higher values for items 5, 16, 18, 22, and 23 (respectively, 0.51, 0.56, 0.53, 0.54, and 0.51), while lower values were associated to items 13,26 , and $30(0.13,0.10$, and 0.16$)$.

The 30-item version of the FSQ-SPF provided numerous indicators for all levels of caregiver problems in this sample. Item values ranged from -1.73 and -1.58 logits (items 1 and 6) to 1.37 and 1.80 logits (items 25 and 30) (mean -0.00; SD 0.88 ). These results closely matched the range of severity levels reported by caregivers, from a low of -2.97 logits with raw score 2/30 to 2.48 logits with raw score 27/30 (mean 0.07; SD 1.20). The Table 1 summarizes the Rasch analysis statistics for the 30 FSQ-SPF items resulting in generally good fit statistics; the values under "estimate" are those values indicated 
by the locations of the items along the Rasch logit scale. The table marks marginal-fit statistics with an asterisk: only indicators for two items show a marginal misfit for the Rasch model. Generally, examination of the output led to a confirmation of the overall results of previous analyses; taking into account that only one item $(\mathrm{n}=13)$ could not be entirely productive for the construction of measurement.

Table 1. Rasch Analysis Statistics for the 30 FSQ-SPF Items Resulting in Generally Good Fit Statistics

\begin{tabular}{|c|c|c|c|c|c|c|}
\hline Item & Estimate & Error & Infit Mn Sq & Outfit Mn Sq & Infit z & $\overline{\text { Outfit z }}$ \\
\hline 1 & -1.58 & 0.27 & 0.94 & 0.82 & -0.40 & -0.60 \\
\hline 2 & -0.93 & 0.24 & 1.14 & 1.15 & 1.30 & 0.80 \\
\hline 3 & 0.40 & 0.23 & 1.15 & 1.20 & 1.60 & 1.50 \\
\hline 4 & -0.87 & 0.24 & 0.94 & 0.86 & -0.60 & -0.70 \\
\hline 5 & -0.49 & 0.23 & 0.85 & 0.78 & -1.70 & -1.50 \\
\hline 6 & -1.73 & 0.28 & 1.03 & 1.23 & 0.20 & 0.80 \\
\hline 7 & 0.03 & 0.23 & 0.98 & 0.89 & -0.20 & -0.80 \\
\hline 8 & -0.22 & 0.23 & 0.91 & 0.83 & -1.00 & -1.30 \\
\hline 9 & 0.19 & 0.23 & 0.85 & 0.78 & -1.70 & -1.80 \\
\hline 10 & -0.59 & 0.23 & 0.92 & 0.84 & -0.80 & -1.00 \\
\hline 11 & -1.11 & 0.25 & 1.00 & 0.91 & 0.10 & -0.30 \\
\hline 12 & 0.50 & 0.23 & 1.07 & 1.09 & 0.70 & 0.70 \\
\hline 13 & -1.24 & 0.25 & 1.26 & 1.57 & 2.00 & 2.20 \\
\hline 14 & -1.44 & 0.26 & 1.09 & 1.27 & 0.70 & 1.00 \\
\hline 15 & 0.50 & 0.23 & 0.97 & 1.21 & -0.30 & 1.40 \\
\hline 16 & 0.50 & 0.23 & 0.81 & 0.75 & -2.10 & -1.90 \\
\hline 17 & 0.50 & 0.23 & 1.12 & 1.20 & 1.20 & 1.40 \\
\hline 18 & -0.17 & 0.23 & 0.98 & 0.94 & -0.20 & -0.40 \\
\hline 19 & 0.34 & 0.23 & 1.08 & 1.11 & 0.80 & 0.80 \\
\hline 20 & -0.12 & 0.23 & 0.95 & 0.88 & -0.60 & -0.90 \\
\hline 21 & 1.00 & 0.24 & 0.96 & 0.91 & -0.30 & -0.50 \\
\hline 22 & 0.66 & 0.23 & 0.82 & 0.77 & -1.90 & -1.60 \\
\hline 23 & -0.38 & 0.23 & 0.86 & 0.77 & -1.60 & -1.70 \\
\hline 24 & 0.45 & 0.23 & 1.00 & 0.98 & 0.00 & -0.10 \\
\hline 25 & 1.37 & 0.26 & 0.91 & 0.81 & -0.70 & -0.80 \\
\hline 26 & 1.31 & 0.25 & 1.24 & 1.41 & 1.80 & 1.70 \\
\hline 27 & 0.50 & 0.23 & 1.21 & 1.22 & 2.10 & 1.50 \\
\hline 28 & 0.24 & 0.23 & 0.93 & 0.93 & -0.80 & -0.50 \\
\hline 29 & 0.56 & 0.23 & 0.93 & 0.92 & -0.70 & -0.50 \\
\hline (*) 30 & 1.80 & 0.28 & 1.22 & 1.19 & 1.40 & 0.70 \\
\hline Mean & 0.00 & 0.24 & 1.00 & 1.01 & -0.10 & -0.10 \\
\hline SD & 0.88 & 0.02 & 0.13 & 0.21 & 1.20 & 1.20 \\
\hline
\end{tabular}

(*) Inverted item

\subsection{Characteristics of the sample and caregivers' strain}

As shown in Table 2, eighty-three subjects were mothers, and 12 were fathers; one subject was the child's aunt who was the primary caregiver. Their mean age was $40.04 \pm 5.8$ years. The unbalanced number of mothers and fathers in our sample mirrors the usual proportion in the caregiving literature, because in the majority of cases, women serve as caretakers. Fifty-two percent of the subjects had one or more children (less than 18 years old) to raise in addition to the child with disabilities. About $40 \%$ referred to the maintenance of social contacts but $54.8 \%$ met friends rarely or never. Nearly $47 \%$ described economic problems caused by the patient's disease, and $17.4 \%$ an insufficient income, although between $67 \%$ and $71 \%$ received some form of welfare benefit to supplement loss of income due to caregiving, which in Italy is generally provided by law to severely disabled people. 
Table 2. Characteristics of the Parents/Caregivers

\begin{tabular}{|l|l|}
\hline Sex $(\mathrm{M} / \mathrm{F})$ & $12 / 84$ \\
Age & $40.04 \pm 5.8(25-55)$ \\
Years of school education & $12.2 \pm 4.03(5-26)$ \\
Marital status & 12 subjects $(12.2 \%)$ separated \\
Definitive cessation from work because of the patient's illness & $29.5 \%$ \\
Temporary stop working because of the patient's illness & $31.6 \%$ \\
Difficulties in the relationship with the partner due to the patient's & $30 \%$ \\
illness & $10.8 \%$ \\
Use of psychotropic drugs & \\
\hline
\end{tabular}

Between $31 \%$ and $40 \%$ declared to have difficulties in reaching hospital to assist the child, if the case, or to take the child to the medical visits. Thirty-one percent did not find any comfort in religion or spirituality. Children they cared for (42 males and 54 females) were 9.2 years old (range 2-17), and 60\% were affected by genetic or congenital diseases, such as cystic fibrosis (13.5\%), and other chromosomal disorders. Acquired diseases, such as neonatal brain injury, affected $36.5 \%$ of the children. In $77 \%$ of cases, the children were diagnosed within the first year of life. Twelve children were diagnosed between 1 and 3 years of age (12\%), seven (7\%) between 4 and 10 years, and 3 children were between 12 and 16 years. Table 3 shows the detailed characteristics of children.

Table 3. Characteristics of the Children

\begin{tabular}{|c|c|}
\hline $\operatorname{Sex}(M / F)$ & $42 / 54$ \\
\hline Age & $9.24 \pm 3.8(2-17)$ \\
\hline School Education (yrs.) & $4.8 \pm 2.7(1-11)(\mathrm{N} .70$ children $)$ \\
\hline $\begin{array}{l}\text { Nutrition: } \\
\text { autonomous } \\
\text { needs partial help } \\
\text { needs total help } \\
\text { PEG or other nutritional device }\end{array}$ & $\begin{array}{l}50.0 \% \\
18.6 \% \\
25.6 \% \\
5.8 \%\end{array}$ \\
\hline $\begin{array}{l}\text { Walking: } \\
\text { autonomous } \\
\text { needs support } \\
\text { unable }\end{array}$ & $\begin{array}{l}41.6 \% \\
15.7 \% \\
42.7 \%\end{array}$ \\
\hline $\begin{array}{l}\text { Dressing: } \\
\text { autonomous } \\
\text { needs partial help } \\
\text { totally dependent }\end{array}$ & $\begin{array}{l}29.1 \% \\
26.7 \% \\
44.2 \%\end{array}$ \\
\hline $\begin{array}{l}\text { Washing: } \\
\text { autonomous } \\
\text { needs partial help } \\
\text { totally dependent }\end{array}$ & $\begin{array}{l}31.4 \% \\
26.7 \% \\
41.9 \%\end{array}$ \\
\hline $\begin{array}{l}\text { Urine control: } \\
\text { continent } \\
\text { sometimes not continent } \\
\text { needs napkins or other }\end{array}$ & $\begin{array}{l}48.2 \% \\
8.2 \% \\
43.5 \%\end{array}$ \\
\hline $\begin{array}{l}\text { Feces control: } \\
\text { continent } \\
\text { sometimes not continent } \\
\text { needs napkins or other }\end{array}$ & $\begin{array}{l}57.1 \% \\
4.8 \% \\
38.1 \%\end{array}$ \\
\hline $\begin{array}{l}\text { Speech: } \\
\text { adequate for age } \\
\text { only some words } \\
\text { unable to speak }\end{array}$ & $\begin{array}{l}55.2 \% \\
29.9 \% \\
14.9 \%\end{array}$ \\
\hline $\begin{array}{l}\text { Comprehension: } \\
\text { total } \\
\text { partial } \\
\text { no comprehension }\end{array}$ & $\begin{array}{l}69.6 \% \\
27.5 \% \\
2.9 \%\end{array}$ \\
\hline $\begin{array}{l}\text { Child's awareness of his/her condition: } \\
\text { total } \\
\text { partial } \\
\text { unaware }\end{array}$ & $\begin{array}{l}39.7 \% \\
36.8 \% \\
23.5 \%\end{array}$ \\
\hline $\begin{array}{l}\text { Child's humor: } \\
\text { happy } \\
\text { a bit happy } \\
\text { unhappy }\end{array}$ & $\begin{array}{l}80.6 \% \\
17.9 \% \\
1.5 \% \\
\end{array}$ \\
\hline
\end{tabular}

Published by Sciedu Press 
The mean total score of FSQ-SPF was $17.4 \pm 5.7$ (range 2-28), indicating that the parents on average placed themselves in area SR, which suggests that they presented evidence of strain requiring psychological examination and counseling. The parents of 33 children and adolescents obtained scores between 21 and 30, which places them in area U, indicating that the caregivers presented great strain and high psychological risk. Thirty-two of the subjects in area $U$ were mothers, and their mean score was $23.3 \pm 2$. These mothers had a mean age of $39 \pm 5$ years (range 30-50) and had a lower level of formal education compared to those with less perceived strain (FSQ SPF $<21)(11 \pm 4$, range 5-19, $p=.05)$. Twelve worked, and 22 lived in households with individuals other than the disabled child and their partner, mostly children under 18 years old $(17 / 22,52 \%)$. A significant portion of these mothers (44\%) described having a more difficult relationship with their partner than the other parents did $(p=.03)$, and 10 said they had insufficient income. No significant difference was observed in the social support systems of the two groups of subjects, nor was any significant difference found in the severity of the children's functional disabilities, speech impairment, comprehension, or emotional well-being. The only significant difference was found in the perception of the children's awareness about their condition: The mothers who were more strained perceived lesser awareness in their child (.004).

\section{Discussion}

Our data showed that parents of children affected by genetic, congenital, and acquired diseases suffer from severe strain independently of the severity of the children's disability. Given that most of the children were diagnosed within their third year of age, it was evident that the parents' adaptation was far from being attained. In particular, more than $40 \%$ declared economic difficulties, reduced social life and problems to move to hospital or for medical visits. About one-third of the sample, composed of mothers, showed great strain and a significant portion of them had a difficult relationship with their partner. These mothers did not present any difference when compared to ones with a lower score on the FSQ-SPF, but a lower level of education, that could limit their access to coping resources and favor the perception of their children as less aware of their own health condition. These data are not surprising, because, in our experience as psychotherapists, a child's illness or death is often described during psychological consultations as the greatest pain in human life by those who are living or who have experienced it. Many internal and external conflicts may arise, and fear for the child's future, if alive after the parents' death, is always present. These emotional worries make it evident that a psychological consultation for these caregivers is not only useful but should be always offered, in the context of the child's medical care, to the parents at greatest risk.

The FSQ-SPF is a useful, practical instrument for the evaluation of caregivers' strain in pediatric and adolescent contexts, especially considering that the available resources to do this are often scarce and health professionals have little time to dedicate, particularly nurses, in spite their direct and constant involvement in the relationship with the parents. The psychometric properties of the FSQ-SPF remain strongly present, and the results can guide health professionals in investigating the parents' difficulties and choosing the appropriate approach. This study, though, was targeted at the parents of children affected by genetic, congenital or acquired diseases, and future studies targeting different children's diseases should be conducted. It is important to note that the interview may be partially modified, adding or eliminating questions in response to a child's specific illness. By itself, the FSQ-SPF does not identify which parents' characteristics, such as personality structure, family dynamics, and ambivalent feelings, should be considered in the implementation of a psychological intervention. Doing so was not the aim of this questionnaire, which had to be brief, practical, and simple enough to be administered by non-psychologists. Given the findings of other authors ${ }^{[17]}$, the FSQ-SPF does, however, serve as an appropriate screening test to indicate the need for a psychological consultation and, thereby, helps to target interventions, ultimately improving the quality of care.

\section{References}

[1] Van Durme T, Macq J, Jeanmart C, Gobert M. Tools for measuring the impact of informal caregiving of the elderly: a literature review. Int J Nurs Stud. 2012; 49(4): 490-504. PMID: 22078211 http://dx.doi.org/10.1016/j.ijnurstu.2011.10.011 
[2] Harvey K, Catty J, Langman A, Winfield H, Clement S, Burns E, White S, Burns T. A review of instruments developed to measure outcomes for carers of people with mental health problems. Acta Psychiatr Scand. 2008; 117(3): 164-76. PMID: 18241311 http://onlinelibrary.wiley.com/doi/10.1111/j.1600-0447.2007.01148.x

[3] Perrin JM, Bloom S and Gortmaker SL. The increase of childhood chronic conditions in the United States. JAMA. 2007; 297(24): 2755-59. PMID: 17595277 http://dx.doi.org/10.1001/jama.297.24.2755

[4] Falk AC, von Wendt L and Klang B. Informational needs in families after their child's mild head injury. Patient Educ Couns. 2008; 70(2): 251-5. PMID: 18037600 http://dx.doi.org/10.1016/j.pec.2007.10.001

[5] Meltzer LJ and Moore M. Sleep disruptions in parents of children and adolescents with chronic illnesses: prevalence, causes, and consequences. J Pediatr Psychol. 2008; 33(3): 279-91. PMID:18084038 http://dx.doi.org/10.1093/jpepsy/jsm118

[6] Murphy NA, Christian B, Caplin DA and Young PC. The health of caregivers for children with disabilities: caregiver perspectives. Child: Care, health and development. 2006; 33(2): 180-87. PMID: 17291322 http:// dx.doi.org/10.1111/j.1365-2214.2006.00644.x

[7] Mentro AM and Steward DK. Caring for medically fragile children in the home: an alternative theoretical approach. Res and Theory for Nursing Pract. 2002; 16(3): 161-77. PMID: 12472292

[8] Meltzer LJ and Mindell JA. Impact of a child's chronic illness on maternal sleep and daytime functioning. Arch Intern Med. 2006; 166: 1749-55. PMID:16983054 http:// dx.doi.org/10.1001/archinte.166.16.1749

[9] Montagnino BA and Mauricio RV. The child with a tracheostomy and gastrostomy: parental stress and coping in the home-a pilot study. Pediatric Nursing. 2004; 30(5): 373-9. PMID:15587530

[10] Cussen A, Sciberras E, Obioha CU and Efron D. Relationship between symptoms of attention-deficit/hyperactivity disorder and family functioning: a community-based study. Eur J Pediatr. 2012; 171: 271-80. PMID: 21743986 http:// dx.doi.org/10.1007/s00431-011-1524-4

[11] Carnevale FA, Alexander E, Davis M et al. Daily living with distress and enrichment: the moral experience of families with ventilator-assisted children at home. Pediatrics. 2006; 117(1): e48-e60. PMID: 16396848 http:// dx.doi.org/10.1542/peds.2005-0789

[12] Parker JA, Mandleco B, Olsen Roper S et al. Religiosity, spirituality, and marital relationship of parents raising a typically developing child or a child with a disability. J Fam Nurs. 2011; 17(1): 82-104. PMID: 21343623 http:// dx.doi.org/10.1177/1074840710394856

[13] Vidotto G, Rossi Ferrario S, Bond TG and Zotti AM. Family Strain Questionnaire - Short form for nurses and general practitioners. J of Clin Nursing. 2010; 19: 275-83. PMID: 20500263 http:// dx.doi.org/10.1111/j.1365-2702.2009.02965.x

[14] Rossi Ferrario S, Baiardi P and Zotti AM. Update on the Family Strain Questionnaire: a tool for the general screening of caregiving-related problems. QURE. 2004; 13: 1425-34. PMID: 15503838

[15] Linacre JM Winsteps (Version 3.68.0) [Computer Software], Chicago, IL: Winsteps.com; 2009.

[16] Rizopoulos D. 1tm: An R Package for Latent Variable Modeling and Item Response Theory Analyses. Journal of Statistical Software 17, Issue 5; 2009.

[17] Barlow JH, Ellard DR. The psychosocial well-being of children with chronic disease, their parents and siblings: an overview of the research evidence base. Child: Care, Health \& Development. 2009; 32(1): 19-31. PMID: 16398788 http:// dx.doi.org/10.1111/j.1365-2214.2006.00591.x 